\section{Comentario sobre tuberculosis ganglionar}

El desafío diagnóstico de la Tuberculosis linfática permanece vigente hasta hoy. No es posible llegar a un diagnóstico seguro en una adenopatía considerada patológica por sus características clínicas o imagenológicas. En esta comunicación breve del Dr. Bouchentouf Rachid ${ }^{1}$, realizada en Marruecos, el autor pone en relieve la necesidad de diferenciar un proceso infeccioso del ganglio patológico de una enfermedad neoplásica (linfoma o metástasis). Finalmente se debe practicar una biopsia quirúrgica de ganglios periféricos o un procedimiento endoscópico de vía aérea o una mediastinoscopía para las localizaciones ganglionares intratorácicas. Sin embargo, este proceso demandó un promedio de 75 días para lograr, en la mayoría de los casos a través de un procedimiento invasivo, el diagnóstico histopatológico. Este plazo se podría acortar notablemente con el uso de la biología molecular. Se menciona que en el hospital donde se realizó esta evaluación, sólo recientemente (2018) se dispone de test diagnóstico basado en biología molecular. La utilidad de la amplificación de ADN de Mycobacterium TBC ha sido destacada en muchos estudios. En nuestro país existe esta tecnología en la plataforma semicuantitativa en tiempo real (GeneXpert MTB/RIF) en todos los servicios de salud apoyada por un manual ministerial $^{2,3}$ que lo recomienda para el estudio de tejido o punción aspirativa de ganglios con una sensibilidad de $85 \%$. Los metaanálisis señalan, basado en los estudios de referencia, una sensibilidad de $79 \%$ considerando como comparativo todas las demás formas de estudio incluida la biopsia, pero que puede alcanzar a $84 \%$ si se considera como comparativo el cultivo de Koch. La sensibilidad en la punción aspirativa del ganglio es mayor que la del procesamiento de las muestras de tejido de las biopsias (90\% versus $76 \%$ ) en los casos comparados con el cultivo del bacilo de $\mathrm{Koch}^{4}$. De manera que una recomendación sería en caso de adenopatías en las que se sospecha tuberculosis entre los diagnósticos diferenciales, practicar inicialmente una punción aspirativa del ganglio para estudio con GeneXpert MTB/RIF. Si no se logra el diagnóstico recurrir a la biopsia con estudio histopatológico y GeneXpert MTB/
RIF del tejido. Es interesante además resaltar que aún existen casos de adenopatías, mayoritariamente submandibulares, probablemente causadas por Mycobacterium Bovis en $12 \%$ de los casos reportados por el autor, en relación con el consumo de leche no pasteurizada. Desafortunadamente el GeneXpert MTB/RIF no puede diferenciar si es el Mycobacterium Bovino o el Humano el que está presente en el paciente, ya que diagnostica un conglomerado denominado "Complejo de Micobacterias" donde ambas especies están incluidas. Es importante recordar que el bacilo Bovino es resistente a la Pirazinamida, pero como podría ser difícil de diferenciar del bacilo Humano si no se tipifica genéticamente, a menudo se utiliza la terapia convencional de la tuberculosis. Además, es necesario aplicar las medidas sanitarias de pasteurización de la leche en esa población rural con el fin de reducir la afectación ganglionar por el bacilo Bovino.

Dr. Carlos Peña Mantinetti Editor Asociado, Sección Tuberculosis. Revista Chilena de Enfermedades Respiratorias

\section{Bibliografía}

1.- RACHID B. Tuberculosis ganglionar: aspectos epidemiológicos, clínicos y evolutivos. Rev Chil Enferm Respir 2021; 37: 82-85.

2.- HERRERA T, ARIAS F, RUIZ N. Manual operativo. Implementación de GeneXpert MTB/RIF en el Programa de Tuberculosis. 2017. Ministerio de Salud. Gobierno de Chile. Disponible en: https://diprece.minsal.cl/wrdprss_minsal/wp-content/uploads/2018/02/2018.01.23_ MANUAL-XPERT.pdf.

3.- HORNE DJ, KOHLI M, ZIFODYA JS, SCHILLER I, DENDUKURI N, TOLLEFSON D, et al. Xpert MTB/RIF and Xpert MTB/RIF Ultra for pulmonary tuberculosis and rifampicin resistance in adults June 2019 Cohrane Database of Systematic Reviews 6 (6). DOI: 10.1002/14651858.CD009593.pub4.

4.- YU G, ZHONG F, YE B, XU X, CHEN D, SHEN Y. Diagnostic Accuracy of the Xpert MTB/RIF Assay for Lymph Node Tuberculosis: A Systematic Review and Meta-Analysis. Biomed Res Int. 2019 19;2019:4878240. doi: 10.1155/2019/4878240. PMID: 31236407 ; PMCID: PMC6545759. 